\title{
Development and validation of Dementia Solat Score for detecting cognitive impairment among Muslim patients: A pilot study
}

\author{
${ }^{1}$ Hoon Lang Teh $m D$ MRCP, ${ }^{2}$ Mohd Azri Mohd Suan mbBS $m S c,{ }^{1}$ Rosnah Ahmad $B$ Nurs Sci, \\ ${ }^{1}$ Muhammad Hafizuddin Yahya $M D$ \\ ${ }^{I}$ Geriatric Unit, Department of Medicine, ${ }^{2}$ Clinical Research Center, Hospital Sultanah Bahiyah, Alor \\ Setar, Kedah, Malaysia.
}

\begin{abstract}
Background \& Objective: Low education and simplicity of lifestyle of Malaysian older adults may mask the early signs of dementia and lead to late presentation with various complications and neglect. From clinical observation, decline in prayer performance in older Muslims might be a sign of cognitive impairment. This study aim to develop and validate an objective assessment tool for dementia based on Muslim routine prayer performance status. Methods: This was a pilot study which involved Muslim participants aged 50 and above. They were divided into normal cognitive control group and cognitive impaired group. Clinical Dementia Rating (CDR) was done on all participants upon recruitment, and Dementia Solat Score (DSS) was done by another group of assessors which were blinded to CDR findings. All the statistical analyses was performed using R statistical software, Version 3.5.2. Results: There were total of 36 participants, 16 from normal cognitive control group and 20 from cognitive impaired group. DSS score was significantly lower in cognitive normal control (median=0, IQR=0) compared to cognitive impaired group (median=4, IQR=9.0), $\mathrm{Z}=-4.54, \mathrm{p}<0.001$. Spearman's rank-order correlation test between CDR and DSS revealed a positive correlation between the two assessment tools, $r=0.920, p<0.001$. The cut-off point of 1 and above in DSS showed a sensitivity of $85.0 \%$, specificity of $93.8 \%$, positive predictive value of $94.4 \%$ and negative predictive value of $83.3 \%$.

Conclusions: This pilot study showed that DSS has high sensitivity and specificity in detecting cognitive impairment among Muslim patients. A higher score in DSS may indicate more severe stage of disease.
\end{abstract}

Keywords: Cognitive impairment, Muslim, prayer performance, assessment tool

\section{INTRODUCTION}

Aging population is a global phenomenon, as average life span is getting longer the prevalence of dementia is expected to be higher. According to the report from Alzheimer's Disease International on the global impact of dementia $2013-2050$, by 2050 there will be 115 millions of people with dementia globally where $58 \%$ of them are from low- and middle-income countries. ${ }^{1}$ Ageing population in low and middle income countries is accelerating in a much faster rate compared to those high income countries. ${ }^{2}$ The rapid rise of dementia incidence and prevalence in these countries will burden their health care services in the future. This vulnerable group of patients is likely to suffer from social neglect and abuse if the low- and middle-income countries are not well prepared for this health care challenge. Hence, World Health Organisation has been calling for global action plan on dementia care since 2017; a framework on 7 action areas was provided as guidance for all especially low- and middleincome countries to improve dementia care. ${ }^{3}$

Dementia care is the most challenging part of elderly care, the disease is not only disabling to the patients but also putting high stress on the carers. However, dementia is still underdiagnosed worldwide, and is often diagnosed at a later stage of disease. ${ }^{4}$ The underdiagnoses is more prevalent in Asia countries compared to Western countries, this is partially because of low public awareness and lack of locally appropriate dementia assessment and screening tools. Studies showed that majority of the existing cognitive assessment tools are educational and language bias. ${ }^{5}$ It is hard

Address correspondence to: Hoon Lang Teh, Geriatric Unit, Department of Medicine, Hospital Sultanah Bahiyah, KM 6, Jalan Langgar, 05460 Alor Setar, Kedah, Malaysia. Email: hoonlang@yahoo.com

Date of Submission: 4 April 2021; Date of Acceptance: 25 August 2021

https://doi.org/10.54029/2021npw 
to standardize the dementia assessment tools in Asia countries due to the diversity in language, ethnic, cultural and educational background. Although Clinical Dementia Rating Scale (CDR) is one of the gold standard dementia assessment scales used worldwide without significant bias across Asian countries ${ }^{6}$, it is time consuming which required average 20-40 minutes to administer. ${ }^{7}$ Development of cultural and language appropriate dementia assessment and screening tools may facilitate Asia countries to increase the detection rate for cognitive impairment.

Malaysia is a multi-ethnic, multi-religion, multi-lingual country situated at South East Asia. The literacy rate of older persons in Malaysia is low especially those residing at rural areas. ${ }^{8}$ The low education level and simplicity of lifestyle of older population at Malaysia rural areas may mask the early signs of dementia and leading to underdiagnoses. However, from local clinical experience, error in performing routine prayer for Muslims correlate with dementia regardless of gender and educational background.

Islam is the official religion of Malaysia where $61.3 \%$ of the population are Muslims. ${ }^{9}$ The five times daily Muslim prayer (also known as solat) throughout the day, is a hallmark of Islam. Solat is the second of the five pillars in Islam and it has been taught and practiced since childhood. Muslim prayer is a complex brain function process which involves not only cognitive functions but also motor and coordination functions. It requires all Muslims to worship five times daily at specific time of the day; at dawn before sunrise (Fajr), midday (Dhuhr), afternoon (Asr), after sunset (Maghrib) and night (Isha). Muslim prayer involves rakaat, a sequence of movements and postures such as standing, bowing, kneeling and touching the ground with the forehead while reciting specific verses from the Quran. Each specific timing of prayer has a different number of required rakaat, ranging from two to four. The ability of elderly Muslim to perform their routine prayer at a designated time, follow a sequence of movements correctly and recite the prayer verses coherently, indicates a reasonably good cognitive functions in memory, attention, language, time orientation and praxis. All these cognitive domains are part of diagnostic criteria for dementia. Thus, the hypothesis we made was measuring functional change objectively in elderly Muslim prayer performance may have clinical value in differentiating cognitive impaired from normal cognitive Muslims. This study was the pilot study aim to develop and validate an objective assessment tool for dementia in Muslims population based on their routine prayer performance.

\section{METHODS}

\section{Ethics and study setting}

The Medical Research Ethics Committee, Ministry of Health Malaysia has approved the conduct of this study (NMRR-20-116-52807). This pilot study was conducted at Memory Clinic, Hospital Sultanah Bahiyah (HSB), a tertiary reference centre for Kedah state, Malaysia. The clinic is led by a geriatrician and a nurse with post basic gerontology background with the help from medical officers. Detailed history taking, cognitive assessment, functional assessment and behavioural assessment were done for every Memory Clinic patient with proper documentation and charting.

\section{Instrument development}

Dementia Solat Score (DSS) was developed based on clinical observation at Memory Clinic, HSB . The problems or issues encountered by Muslims with dementia during their routine prayer were documented in the clinic review notes. The Memory Clinic team looked through the clinic notes from 2017 until 2019 and listed out the problems or issues encountered by Muslims with dementia during their routine prayer. After analysing the listed-out prayer errors, the team managed to group issues or problems into five major category and correlate with the respective cognitive domains. The team also discussed with hospital Ustaz (Islamic Religion Teacher) on the practicality of creating a scoring system on prayer performance.

The five prayer performance indicators identified were as below:

(1). The ability to pray five times daily. Patients with impaired recent memory tend to forget whether they have performed their prayer at the specific time of the day. Some Muslims with dementia were reported of performing their prayer repeatedly for more than five times per day, while some performed less than five times per day.

(2). The ability to pray according to the schedule time. Praying at wrong timing was reported by the carers for those Muslims with dementia due to disorientation to time. Some patients prayed at weird timing like middle of the night, and some 
missed their prayers if not reminded.

(3). Perform ablution (wudhuk) before prayer. Ablution is a ritualistic washing of hands, feet, arms and legs in a specific sequence in order to clear one's mind and body before starting prayer. Those with impaired cognition had tendency to perform ablution repeatedly or forget to perform it before prayer. Some patients were reported of performing ablution in wrong sequence, this error could be due to impaired procedural memory.

(4). Recite prayer verses. Recitation of prayer verses required a person to have reasonably good attention, good remote memory and language function to perform the task. Some patients were noted to either reciting the prayer verses in wrong sequence or repeating it unnecessarily. Problem with articulation also reported by the carers which might be due to deterioration in language function.

(5). Follow correct sequence of movements during prayer. Some Muslims with dementia were found to perform the steps of movements during prayer in wrong sequence, this might be due to impaired procedural memory and attention. There were also some carers reported about patients performed the movements in an uncoordinated way which could be due to decline in praxis. A reasonably good attention, long-term (procedural) memory, motor function and coordination are required to complete this task.

This categorization of prayer performance indicators were finalised after discussion between the clinical experts and hospital Ustaz (Islamic Religion Teacher). Its potential association with cognitive domains is summarised in Table 1 . A three-point scale ( 0 to 2 ) was chosen as the response format for each prayer performance indicator. The score was given based on the person's performance on their routine prayer for the past 1 month after interviewing their carer. The final version of the DSS assessment tool is shown in Table 2, with minimum score of 0 and maximum score of 10 , higher DSS total score will indicate greater degree of functional impairment.

\section{Dementia Solat Score (DSS) validation}

The final version of DSS was checked for its validity by comparing it with Clinical Dementia Rating (CDR) score. ${ }^{6,10}$ Both cognitive impaired and cognitive normal subjects were recruited for this pilot study. Only Muslims aged 50 years old and above were eligible for the study recruitment. Those with significant neurological deficits due to other diseases apart from Dementia were excluded from the study.

Cognitive impaired group consists of patients with mild neurocognitive disorder (Mild cognitive impairment - MCI) and major neurocognitive disorder (Dementia) who scored 0.5 and above in CDR. The diagnosis of mild neurocognitive disorder and major neurocognitive disorder was made based on Diagnostic Statistic Manual Fifth Edition (DSM-V) diagnostic criteria. The terms mild neurocognitive disorder and major neurocognitive disorder were used interchangeably with MCI and dementia., ${ }^{11,12}$ Cognitive normal controls were those with no cognitive problem and scored 0 in CDR.

Study recruitment was started from June 2019 until February 2020 at Hospital Sultanah Bahiyah (HSB). A minimum of 12 patients were required for each group based on the recommendation by Julious on sample size for pilot study. ${ }^{13}$ Cognitive impaired participants were enrolled into this

Table 1: Categorization of Muslim prayer performance indicators and its association with cognitive domains

\begin{tabular}{lll}
\hline & Prayer Performance Indicators & Cognitive Domain(s) \\
\hline 1 & Pray five times daily & Short term memory \\
2 & Pray according to the schedule time & Orientation to time of the day \\
3 & Perform ablution (Wudhuk) before prayer & $\begin{array}{l}\text { Short term memory } \\
\text { Long term memory - Procedural memory }\end{array}$ \\
& & Attention \\
& Recite prayer verses & Language \\
& & Long term memory - Semantic memory \\
5 & Perform steps of movements during prayer & Attention \\
& & Long term memory - Procedural memory \\
& Motor function and coordination \\
\hline
\end{tabular}


Table 2: Dementia Solat Score scoring format

\begin{tabular}{|c|c|c|c|c|}
\hline & $\begin{array}{l}\text { Prayer Performance } \\
\text { Indicators }\end{array}$ & $\mathbf{0}$ & 1 & 2 \\
\hline 1 & Pray five times daily & $\begin{array}{l}\text { Performed prayers } \\
\text { five times daily }\end{array}$ & $\begin{array}{l}\text { Performed prayers more } \\
\text { or less than five times } \\
\text { daily }\end{array}$ & $\begin{array}{l}\text { Did not perform any } \\
\text { prayer }\end{array}$ \\
\hline 2 & $\begin{array}{l}\text { Pray according to } \\
\text { the schedule time }\end{array}$ & $\begin{array}{l}\text { Followed the } \\
\text { schedule time } \\
\text { correctly }\end{array}$ & $\begin{array}{l}\text { Did not follow the } \\
\text { schedule time } \\
\text { Or } \\
\text { Followed the schedule } \\
\text { time with reminder from } \\
\text { carer }\end{array}$ & $\begin{array}{l}\text { Did not perform any } \\
\text { prayer }\end{array}$ \\
\hline 3 & $\begin{array}{l}\text { Perform ablution before } \\
\text { prayer }\end{array}$ & $\begin{array}{l}\text { Performed ablution } \\
\text { before prayer } \\
\text { independently }\end{array}$ & $\begin{array}{l}\text { Performed ablution } \\
\text { before prayer with } \\
\text { reminder or instruction } \\
\text { from carer } \\
\text { Or } \\
\text { Performed ablution } \\
\text { before prayer repeatedly } \\
\text { or with errors }\end{array}$ & $\begin{array}{l}\text { Did not perform } \\
\text { ablution before } \\
\text { prayer despite } \\
\text { reminder or } \\
\text { instruction given by } \\
\text { carer }\end{array}$ \\
\hline 4 & Recite prayer verses & $\begin{array}{l}\text { Recited prayer verses } \\
\text { independently }\end{array}$ & $\begin{array}{l}\text { Recited prayer verses } \\
\text { with assistance or } \\
\text { guidance from carer } \\
\text { Or } \\
\text { Recited prayer verses } \\
\text { independently but with } \\
\text { error(s) }\end{array}$ & $\begin{array}{l}\text { Unable to recite } \\
\text { prayer verses despite } \\
\text { with assistance or } \\
\text { guidance from carer }\end{array}$ \\
\hline 5 & $\begin{array}{l}\text { Perform steps of } \\
\text { movements during } \\
\text { prayer }\end{array}$ & $\begin{array}{l}\text { Performed steps of } \\
\text { movements during } \\
\text { prayer independently }\end{array}$ & $\begin{array}{l}\text { Performed steps of } \\
\text { movements during } \\
\text { prayer with assistance } \\
\text { or guidance from carer } \\
\text { Or } \\
\text { Performed steps of } \\
\text { movements during } \\
\text { prayer independently } \\
\text { but with error(s) }\end{array}$ & $\begin{array}{l}\text { Unable to perform } \\
\text { steps of movements } \\
\text { during prayer despite } \\
\text { with assistance or } \\
\text { guidance from carer }\end{array}$ \\
\hline
\end{tabular}

* The score was given based on the person's performance on their routine prayers for the past 1 month by interviewing their carer

* The carer must be the one who stayed with the study subject for past one month or who visited the study subject at least once a week for past one month.

pilot study from Memory Clinic HSB, whereas cognitive normal group participants were either the spouse of those cognitive impaired persons or recruited from General Geriatric Clinic HSB.

All assessments and demographic data collection were done at the same visit after obtaining consent. CDR was done on all participants by the clinic geriatrician, whereas DSS was scored after interviewed the carers by either the clinic nurse or medical officer who were blinded to the CDR score. The carer must be the one who stayed with the study subject for past one month or who had visited the study subject at least once a week for past one month.

\section{Statistical analysis}

Descriptive statistics for demographic data collected were presented in frequency and percentage for categorical data while mean and standard deviation were used for normally distributed numerical data. Between groups comparison was performed using Pearson's Chi-square test for categorical variables while the Independent t-test or Mann-Whitney test for 
numerical variables. Concurrent validity of DSS was determined using Spearman's rank-order correlation coefficient with CDR as standards. Diagnostic performance of DSS was evaluated using the receiver operating characteristic (ROC) curve to determine cut-off point for cognitive impaired patient, sensitivity, specificity, positive and negative predictive values. The significance level was fixed at $p<0.05$. All the above statistical analyses were performed using the $\mathrm{R}$ statistical software, Version 3.5.2..$^{14}$

\section{RESULTS}

\section{Baseline characteristics}

A total of 36 participants were recruited for this pilot study, 20 of them had cognitive impairment while another 16 participants were in the normal cognitive control group. The mean age was 71.9 years old, and female gender was slightly predominant $(n=20,55.6 \%)$. The proportion of married participants and educational attainment were almost the same between both groups and no significant difference were found. Of those participants in the cognitive impaired group, 3 of them had MCI and 17 of them were diagnosed with dementia. Out of 17 participants with dementia, 5 of them were in early stage of dementia with CDR score of 1,6 were moderate stage with CDR score of 2 and another 6 participants were in severe stage of dementia with CDR score of 3 . Vascular dementia was the most prevalence type of dementia in this group of patients, followed by Alzheimer's disease, mixed dementia, Lewy body dementia and Parkinson disease dementia. Other characteristics of study participants were summarized in Table 3.

Table 3: Baseline characteristics of normal cognitive and cognitive impaired participants

\begin{tabular}{|c|c|c|c|c|c|}
\hline \multirow[t]{2}{*}{ Variables } & \multicolumn{2}{|c|}{$\begin{array}{c}\text { Normal cognitive } \\
(\mathbf{N}=16)\end{array}$} & \multicolumn{2}{|c|}{$\begin{array}{c}\text { Cognitive impaired } \\
(\mathbf{N}=\mathbf{2 0})\end{array}$} & \multirow[t]{2}{*}{ p value } \\
\hline & $\mathbf{n}$ & $(\%)$ & $\mathbf{n}$ & $(\%)$ & \\
\hline Age (years), mean, SD & 71.4 & $(9.27)$ & 72.4 & $(10.03)$ & $0.766^{\mathrm{a}}$ \\
\hline Ethnicity & & & & & $0.364^{\mathrm{b}}$ \\
\hline Malays & 16 & $(100.0)$ & 19 & $(95.0)$ & \\
\hline Non-Malays & 0 & & 1 & $(5.0)$ & \\
\hline Gender & & & & & $0.154^{\mathrm{b}}$ \\
\hline Male & 5 & $(31.2)$ & 11 & $(55.0)$ & \\
\hline Female & 11 & $(68.8)$ & 9 & $(45.0)$ & \\
\hline Marital status & & & & & $0.739^{\mathrm{b}}$ \\
\hline Married & 12 & $(75.0)$ & 14 & $(70.0)$ & \\
\hline Divorced / Widower & 4 & $(25.0)$ & 6 & $(30.0)$ & \\
\hline \multicolumn{6}{|l|}{ Educational Attainment } \\
\hline No formal education / Primary & 3 & $(18.8)$ & 4 & $(20.0)$ & $0.925^{\mathrm{b}}$ \\
\hline Secondary / Tertiary & 13 & $(81.2)$ & 16 & $(80.0)$ & \\
\hline \multicolumn{6}{|l|}{ CDR Score } \\
\hline 0 & 16 & $(100.0)$ & 0 & & \\
\hline 0.5 & 0 & & 3 & $(15.0)$ & \\
\hline 1 & 0 & & 5 & $(25.0)$ & \\
\hline 2 & 0 & & 6 & $(30.0)$ & \\
\hline 3 & 0 & & 6 & $(30.0)$ & \\
\hline \multicolumn{6}{|l|}{ Subtypes of Dementia } \\
\hline Mild cognitive impairment & NR & & 3 & $(15.0)$ & \\
\hline Alzheimer's Disease & $\mathrm{NR}$ & & 4 & $(20.0)$ & \\
\hline Lewy Body Dementia & NR & & 2 & $(10.0)$ & \\
\hline $\begin{array}{l}\text { Parkinson Disease } \\
\text { Dementia }\end{array}$ & $\mathrm{NR}$ & & 2 & $(10.0)$ & \\
\hline Vascular Dementia & $\mathrm{NR}$ & & 5 & $(25.0)$ & \\
\hline Mixed Dementia & NR & & 4 & $(20.0)$ & \\
\hline
\end{tabular}

$\mathrm{SD}=$ standard deviation, $\mathrm{a}=$ independent $\mathrm{t}$-test, $\mathrm{b}=$ chi-square test, $\mathrm{NR}=$ not relevant 
Table 4: The DSS and CDR total score between normal cognitive and cognitively impaired participants

\begin{tabular}{lllllll}
\hline \multirow{2}{*}{ Variables } & \multicolumn{2}{c}{$\begin{array}{c}\text { Normal cognitive } \\
(\mathbf{N = 1 6})\end{array}$} & $\begin{array}{c}\text { Cognitive impaired } \\
(\mathbf{N = 2 0})\end{array}$ & Z-stat. & p value $^{\mathbf{c}}$ \\
\cline { 2 - 8 } & med & $(\mathbf{I Q R})$ & med & $(\mathbf{I Q R})$ & & \\
\hline DSS Total score & 0 & $(0.0)$ & 4 & $(9.0)$ & -4.54 & $<0.001$ \\
CDR Total score & 0 & $(0.0)$ & 2 & $(2.0)$ & -5.37 & $<0.001$ \\
\hline
\end{tabular}

$\mathrm{Z}$-stat=Z statistic, Med=median, $\mathrm{IQR}=$ inter quartile range, $c=$ Mann-Whitney test

\section{$D S S$ and $C D R$ scores}

Comparison for DSS and CDR scores between both groups showed that DSS score was significantly lower in cognitive normal control (median=0, IQR=0) compared to cognitive impaired group (median=4, IQR=9.0, $\mathrm{Z}=-4.54$, $\mathrm{p}<0.001)$. Likewise, total score of CDR was also significantly different between both groups (Table 4). Table 5 depict correlation analysis between DSS and CDR total score, memory domain and orientation domain. For CDR total score, the Spearman's rank-order correlation test revealed a positive correlation between the two assessment tools, $r=0.920, p<0.001$, which suggests a very high correlation..$^{15}$ A positive strong correlation was also shown between DSS and CDR in both memory and orientation domain.

\section{Diagnostic performance of DSS}

The area under ROC curve for DSS to predict cognitively impaired patient was $91.6 \%(95 \%$ CI: 82.9\%-99.1\%), which considered an excellent discrimination (Figure 1). ${ }^{16}$ The optimal cut-off DSS value to predict the presence of cognitive

Table 5: Spearman's correlation coefficients (r) of the DSS total score and the CDR total score

\begin{tabular}{lccccccc}
\hline \multirow{2}{*}{ Variable } & \multicolumn{2}{c}{ CDR Total score } & \multicolumn{2}{c}{$\begin{array}{c}\text { CDR Memory } \\
\text { domain }\end{array}$} & \multicolumn{2}{c}{$\begin{array}{c}\text { CDR Orientation } \\
\text { domain }\end{array}$} \\
\cline { 2 - 8 } & r value & p value $^{\mathbf{d}}$ & r value & p value $^{\mathbf{d}}$ & r value $^{\text {p value }^{\mathbf{d}}}$ \\
\hline DSS Total score & 0.920 & $<0.001$ & - & - & - & - \\
DSS Memory domain & - & - & 0.879 & $<0.001$ & - & - \\
DSS Orientation domain & - & - & - & - & 0.933 & $<0.001$ \\
\hline
\end{tabular}

$\mathrm{d}=$ Spearman's Rank-Order Correlation

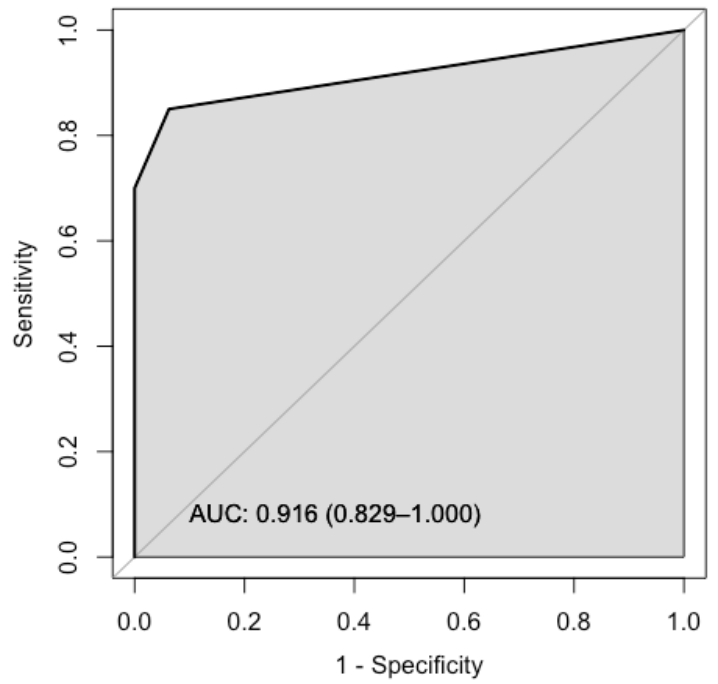

Figure 1. Internal validation of DSS for predicting cognitive impairment among Muslim patients. $\mathrm{AUC}=$ area under curve 
Table 6: Diagnostic performance of DSS at the optimal cut off value of 1 for assessing cognitive impairment in Muslim patients

\begin{tabular}{llllll}
\hline $\begin{array}{l}\text { Optimal } \\
\text { Threshold }\end{array}$ & $\begin{array}{l}\text { Area under ROC } \\
\text { curve }(\mathbf{9 5 \%} \text { CI) }\end{array}$ & $\begin{array}{l}\text { Sensitivity } \\
(\mathbf{9 5 \%} \text { CI*) }\end{array}$ & $\begin{array}{l}\text { Specificity } \\
(\mathbf{9 5 \%} \text { CI*) }\end{array}$ & $\begin{array}{l}\text { PPV } \\
(\mathbf{9 5 \%} \text { CI*) }\end{array}$ & $\begin{array}{l}\text { NPV } \\
(\mathbf{9 5 \%} \text { CI*) }\end{array}$ \\
\hline 1.0 & 91.6 & 85.0 & 93.8 & 94.4 & 83.3 \\
& $(82.9-100.0)$ & $(67.3-98.9)$ & $(81.3-100.0)$ & $(84.1-100.0)$ & $(65.0-80.1)$ \\
\hline
\end{tabular}

Abbreviation: $\mathrm{ROC}=$ receiver operating characteristic, $\mathrm{CI}^{*}=$ bootstrap confidence interval, $\mathrm{PPV}=$ positive predictive value, $\mathrm{NPV}=$ negative predictive value

impairment was 1.0 and above as shown in Table 6. At this cut-off value, DSS showed a sensitivity of $85.0 \%$, specificity of $93.8 \%$, positive predictive value of $94.4 \%$ and negative predictive value of $83.3 \%$. Diagnostic performance of other DSS cut-off values were presented in Table 7.

\section{DISCUSSION}

This DSS was developed based on the routine daily prayer performance among Muslims with the intention to make it easy to use, short administration time and practical. Even a nonMuslim and a non-health care professional should be able to use it for assessment without much training. The average time for administration for DSS was about 2 minutes per patient. From the data analysis it showed that DSS demonstrated a good performance in differentiating cognitive impaired and normal cognitive groups with high sensitivity of $85.0 \%$ and high specificity of $93.8 \%$ at the cut-off point of 1 .

From clinical observation done at Memory Clinic HSB, those with early dementia usually presented with repeating the same prayer several times and repeating the prayer rituals unnecessarily. As the disease progress, when patients got more confuse with time orientation during moderate stage of disease, they had tendency to pray at wrong timing. They were also found struggling with prayer verses recitation and prayer movements during moderate stage of dementia. Whereas advance dementia patients usually gave up prayer or unable to perform it even with reminder and guidance from carers. The strong correlation of DSS with CDR ( $r$ value 0.92 , p value $<0.001$ ) indicates that DSS can be used as a guide for disease staging.

An ideal assessment scale for dementia would be a scale which is practical, easy and quick to administer, validated for use in dementia, involved multi-domains assessment, applicable to all dementia severity stages, able to monitor disease progression, and sensitive to measure therapy effects. ${ }^{17}$ DSS is having most of the criteria as an ideal assessment tool except it might not be sensitive enough to detect change in therapeutic

Table 7: The Dementia Solat Score threshold values and respective sensitivity, specificity, positive predictive value, negative predictive value and accuracy

\begin{tabular}{llllll}
\hline Score Threshold & Sensitivity & Specificity & PPV & NPV & Accuracy \\
\hline 0 & 100.0 & 0 & 55.6 & NA & 55.6 \\
1 (optimal) & 85.0 & 93.8 & 94.4 & 83.3 & 88.9 \\
2 & 70.0 & 100.0 & 100.0 & 72.7 & 83.3 \\
3 & 70.0 & 100.0 & 100.0 & 72.7 & 83.3 \\
4 & 60.0 & 100.0 & 100.0 & 66.7 & 77.8 \\
5 & 45.0 & 100.0 & 100.0 & 59.3 & 69.4 \\
6 & 40.0 & 100.0 & 100.0 & 57.1 & 66.7 \\
7 & 35.0 & 100.0 & 100.0 & 55.2 & 63.9 \\
8 & 35.0 & 100.0 & 100.0 & 55.2 & 63.9 \\
9 & 30.0 & 100.0 & 100.0 & 53.3 & 61.1 \\
10 & 30.0 & 100.0 & 100.0 & 53.3 & 61.1 \\
\hline
\end{tabular}

Abbreviation: $\mathrm{CI}=$ bootstrap confidence interval, $\mathrm{PPV}=$ positive predictive value, $\mathrm{NPV}=$ negative predictive value 
effects. The change in functional status after an intervention for person with dementia can be very minute and yet significant, usually a more detail and complex scale is required to assess the pre and post intervention therapeutic effects. However, we think DSS has the potential to be expanded into a more extensive assessment scale which might be useful to measure therapy effects.

At the moment there is generally still no curative treatment available for dementia, hence early diagnosis with symptomatic control are the main stay of disease management approach to improve quality of life, reduce carer burden, prevent neglect and abuse on these vulnerable group of patients. The contributing factors for underdiagnoses could be due to low public awareness, low education level and low social economy status. ${ }^{18}$ In the local community, the public especially those from rural areas tend to seek treatment from traditional healers and religion preachers when they are unwell leading to late presentation and delay in diagnosis. The statistics collected in our hospital showed that $49 \%$ of the patients presented to memory clinic were already at moderate or severe stage of disease, only $6 \%$ of them presented with MCI and $46 \%$ were diagnosed dementia at the early stage of disease. It is not uncommon to see dementia patients presented late with falls and injuries, neglected with pressure ulcers or aspiration pneumonia. Most of them had lost their mental capacity to make decision at the time of diagnosis and missed the golden opportunity for advance care planning discussion to preserve their autonomy in the future care management.

We believe DSS could be significant for dementia care in Malaysia because majority of our population are Muslims. Public tend to assume the early signs and symptoms of dementia are part of normal ageing process, with DSS we can use the influence of Muslim religion preachers to raise the public awareness on decline in routine prayer performance could be an early warning signs of dementia too. There is one study showing that adherence to prayer among female Muslims were associated with lower prevalence of dementia ${ }^{19}$, hence we believe that guided prayer or structured prayer retraining program could be one of the effective cognitive rehabilitation therapies for Muslims with dementia. A systematic review on spirituality and religion in older adults with dementia showed that engagement with religion and spiritual activity appeared to slow cognitive decline, improve coping strategies and improve quality of life.$^{20}$ However the existing evidence was not robust and further research is needed. DSS is a first step in exploring the effect of Muslim prayer in relationship with dementia in a more objective and systematic approach.

The strength of the DSS include involving multiple cognitive domains assessment which are important in making clinical diagnosis of Dementia. It also contained evaluation of motor and coordination functions which decline at the later stage of disease. Nevertheless, we noticed that the DSS might not be able to differentiate MCI from normal cognitive function. There were total of $3 \mathrm{MCI}$ patients in the cognitive impaired group, and all of them scored 0 for DSS which was same score as majority of the normal cognitive subjects. This can be due to the fact that MCI patients who came to the memory clinic for follow-up were those with higher education background and more concerned on their cognitive performance. Some of them set prayer reminder on their smartphone or home alarm to remind them to pray at the correct time. This finding correspond to the diagnostic criteria for MCI, where the decline in cognitive function should not affect a patient's daily routine. We have tried to remove the data of those MCI participants for reanalysis, it did not affect the cut-off point, with little effect in sensitivity, specificity and correlation analysis. Small sample size in this pilot study also contributed to this limitation. Thus, further study with larger sample size is required before firm conclusion can be made.

Another limitation of DSS is the scoring is totally dependent on the carer, hence it is not applicable to patients who stay alone unless the patients had fixed a CCTV to record their daily routine which can capture their prayer activities at home. We assumed that the carers that involved in this pilot study were cognitively intact based on the clinician's judgement after interviewed them during CDR assessment. There was no formal objective cognitive assessment done for the carers prior to enrolment. Other limitation relates to the DSS applicability only on Muslim individuals that practise 5 times daily prayer as their routine before the onset of cognitive decline. Nonetheless, there are approximately two billion Muslims in the world and vast majority of them are residing in low- and middle-income countries. ${ }^{21}$ The rapid rise in dementia incidence and prevalence at this part of the world are putting millions of vulnerable older adults at risk of neglect and poor care, hence early detection with cultural specific assessment tool like DSS would be beneficial. DSS has the potential to be used by the public to 
check on their elders at home or in the mosques, and it also has potential to evolve to become a cognitive assessment tool which can detect MCI by adding more detail errors description in the scoring categories. For example, in prayer time, we can expand the scoring from $0-2$ to $0-3$ by adding using any alarm reminder for prayer.

In conclusion, this pilot study showed that DSS has high sensitivity and specificity in differentiating cognitive impaired from cognitive normal patients. A higher score in DSS may indicate more severe stage of disease as it has shown high correlation with CDR. It is a quick, easy to administer, practical and non-educational bias assessment scale, but it requires a reliable informant to help in scoring and only applicable on Muslims. Further study with multi centres and multi regions design is needed to further examine the validity of DSS.

\section{ACKNOWLEDGEMENTS}

The authors would like to thank Ustaz Mohamad Ismudi Sanusi from Hospital Sultanah Bahiyah for his help in developing DSS. We also thank the Director General of Health Malaysia for his permission to publish this article.

\section{DISCLOSURE}

Financial support: None

Conflicts of interest: None

\section{REFERENCES}

1. Prince M, Guerchet M, Prina M,Alzheimer's Disease International. Policy brief for heads of government: The Global impact of dementia 2013-2050. London: Alzheimer's Disease International, 2013.

2. World Health Organization. World report on ageing and health. Luxembourg: World Health Organization, 2015.

3. World Health Organization. Global action plan on public health response to dementia 2017-2025. Geneva: World Health Organization, 2017.

4. Lang L, Clifford A, Wei L, et al. Prevalence and determinants of undetected dementia in the community: A systematic literature review and a meta-analysis. BMJ Open 2017; 7:e011146.

5. Rosli R, Tan MP, Gray WK, Subramanian P, Chin A. Cognitive assessment tools in Asia: A systematic review. Int Psychogeriatr 2016; 28(2):189-210.

6. Lim WS, Chong MS, Sahadevan S. Utility of the clinical dementia rating in Asian populations. Clin Med Res 2007; 5(1):61-70.

7. Rikkert MGMO, Tona KD, Janssen L, et al. Validity, reliability, and feasibility of clinical staging scales in dementia: A systematic review. Am J Alzheimers Dis Other Demen 2011; 26(5):357-65.
8. Malaysia elderly literacy rate, $1970-2018$. World Data Atlas. 2019. Available at: https://knoema.com//atlas/ Malaysia/topics/Education/Literacy/Elderly-literacyrate.

9. Population distribution and basic demographic characteristic report 2010. Department of Statistic Malaysia. 2011. Available at: https:// www.dosm.gov.my/v1/index.php?r=column/ c the me \& m e n u_id $=$ L 0 p h e U 43 N W J w RWVSZklWdzQ4TlhUUT09\&bul_id=MDMxdHZj WTk1SjFzTzNkRXYzcVZjdz09.

10. Hughes CP, Berg L, Danziger WL, Coben LA, Martin RL. A new clinical scale for the staging of dementia. Br J Psychiatry 1982; 140:566-72.

11. American Psychiatric Association. Diagnostic and statistical manual of mental disorders. 4th Ed. Washington: APA; 2000.

12. Stokin GB, Krell-Roesch J, Petersen RC, Geda YE. Mild neurocognitive disorder: An old wine in a new bottle. Harv Rev Psychiatry 2015; 23(5):368-76.

13. Julious SA. Sample size of 12 per group rule of thumb for a pilot study. Pharm Stat 2005; 4:287-91.

14. Team RC. R: A language and environment for statistical computing. Vienna, Austria: R Foundation for Statistical Computing; 2014. 2014.

15. Munro BH. Statistical methods for health care research. 5th Ed. Massachusetts: Lippincott Williams \& Wilkins; 2005.

16. Hosmer DW, Lemeshow S. Applied Logistic Regression. 2nd Ed. New York, NY: John Wiley and Sons, 2000:160-4.

17. Robert P, Ferris S, Gauthier S, Ihl R, Winblad B, Tennigkeit F. Review of Alzheimer's disease scales: Is there a need for a new multi-domain scale for therapy evaluation in medical practice? Alzheimers Res Ther 2010; 2(4):24.

18. Amjad H, Roth DL, Sheehan OC, Lyketsos CG, Wolff JL, Samus QM. Underdiagnosis of dementia: An observational study of patterns in diagnosis and awareness in US older adults. J Gen Intern Med 2018; 33(7):1131-8.

19. Inzelberg R, Afgin AE, Massarwa M, et al. Prayer at midlife is associated with reduced risk of cognitive decline in Arabic women. Curr Alzheimer Res 2013; 10(3):340-6.

20. Agli O, Bailly N, Ferrand C. Spirituality and religion in older adults with dementia: A systematic review. Int Psychogeriatr 2015; 27(5):715-25.

21. Muslim population by country 2020. World Population Review. 2020. Available at: https:// worldpopulationreview.com/countries/muslimpopulation-by-country/. 